\title{
BibleWorks 7
}

by Mark Hangartner

\section{Bibleworks 7}

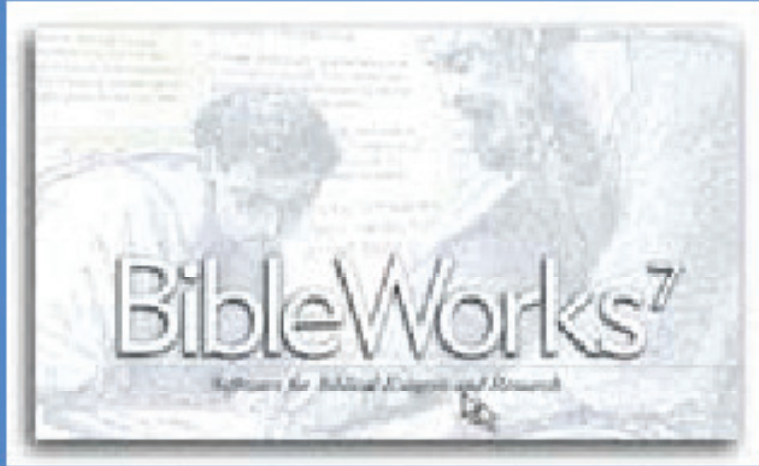




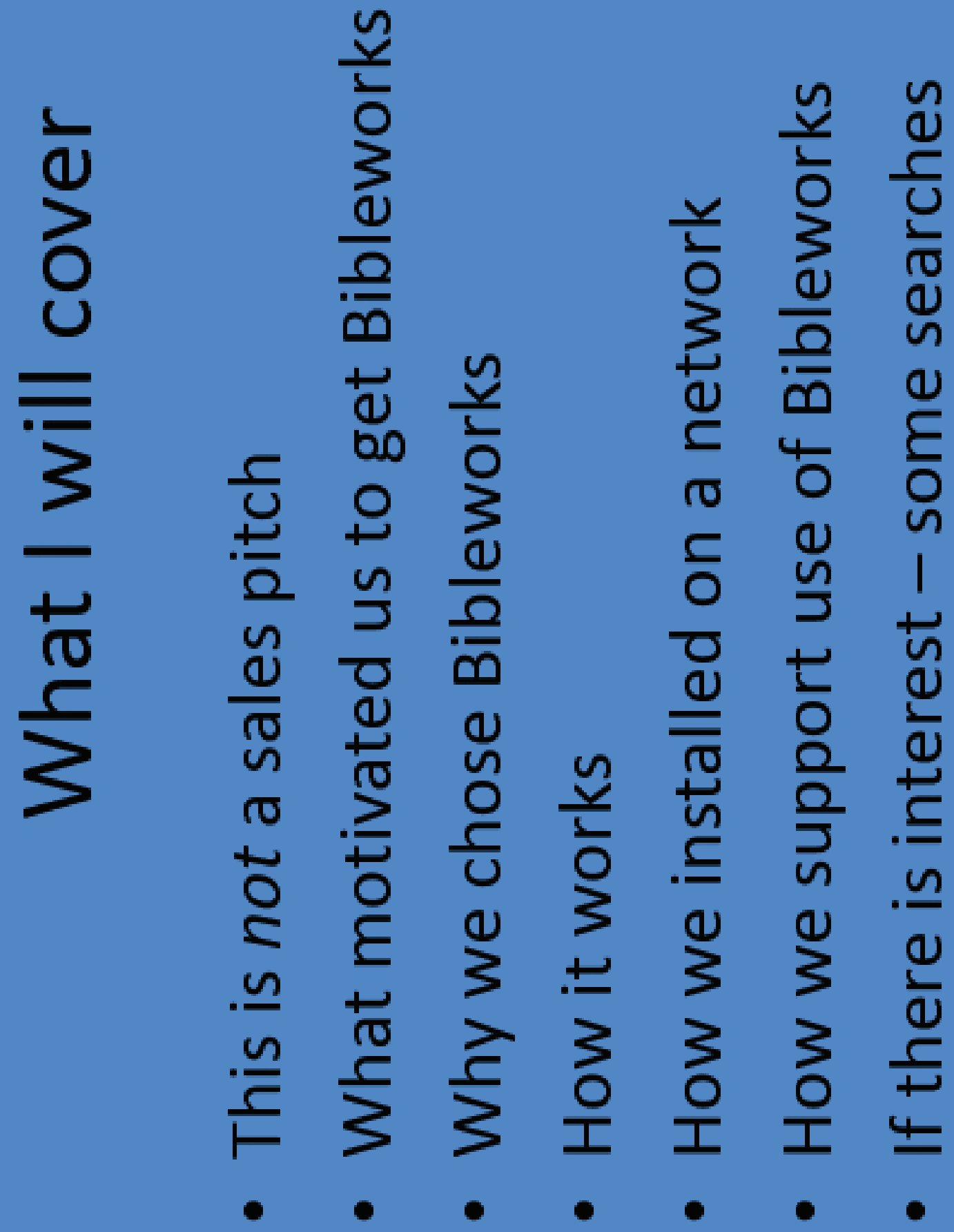




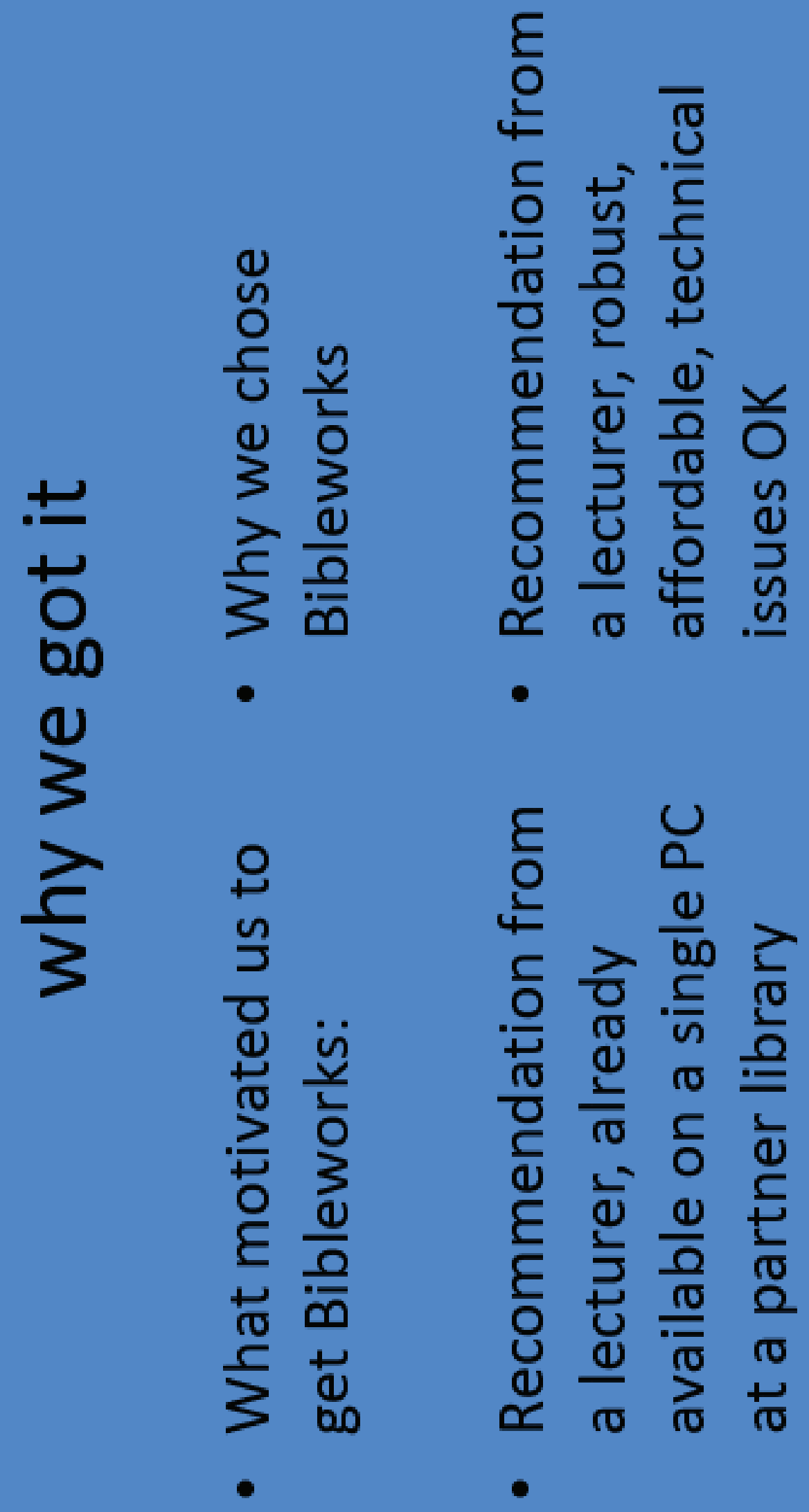




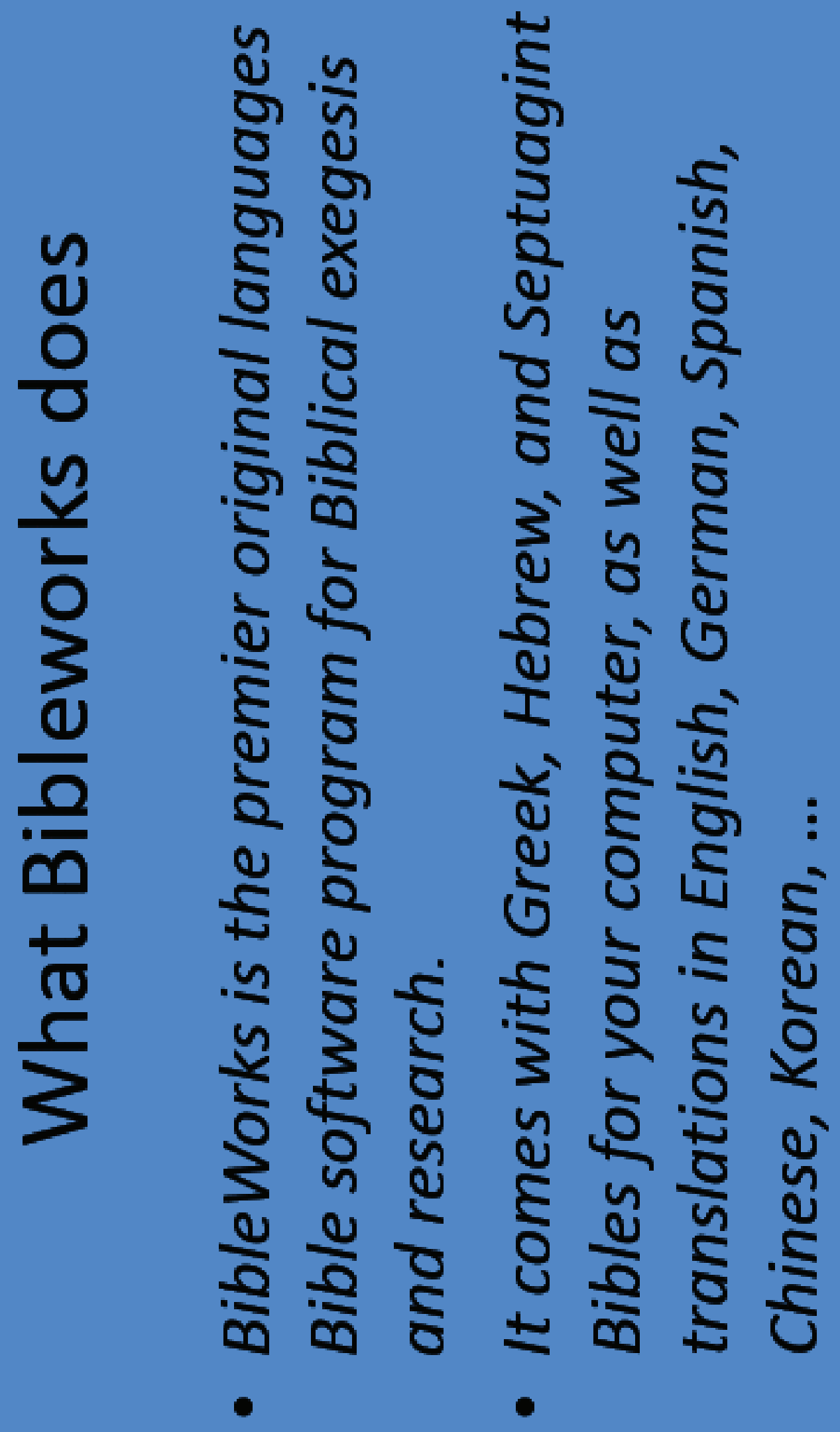




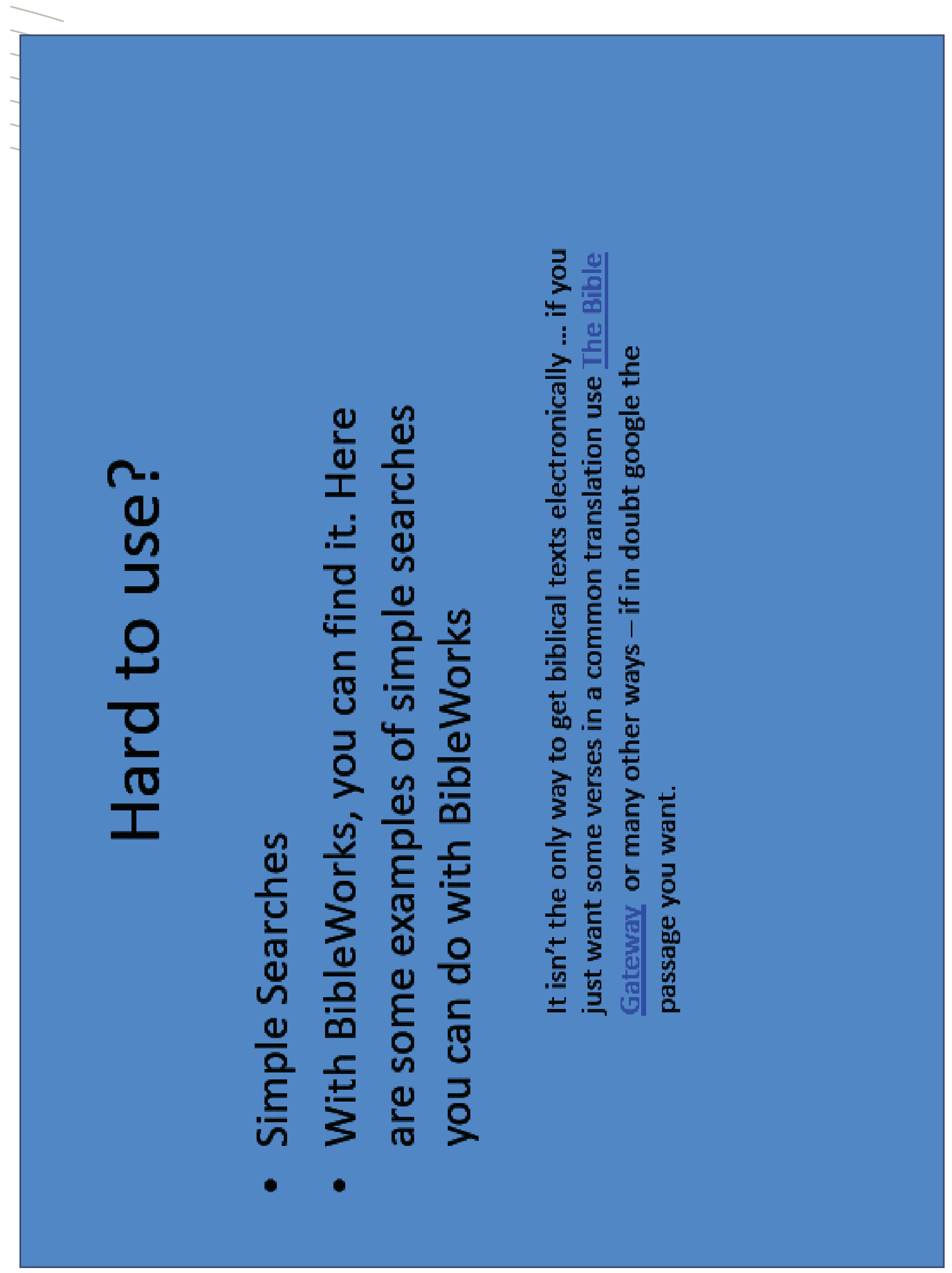


هํ.

उ

중ㅇㅇㅇ 응

उ

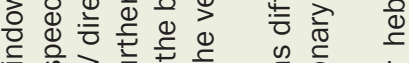

की

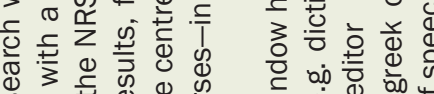

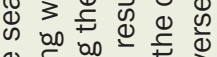

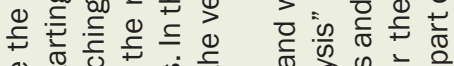

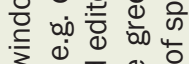

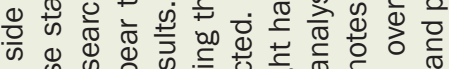

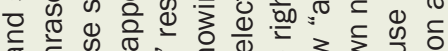

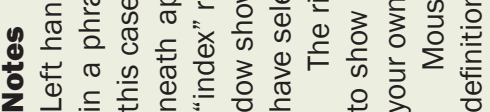

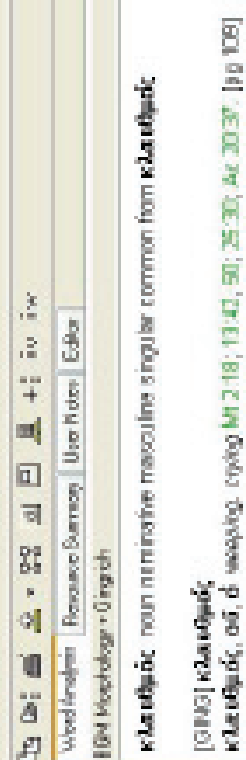

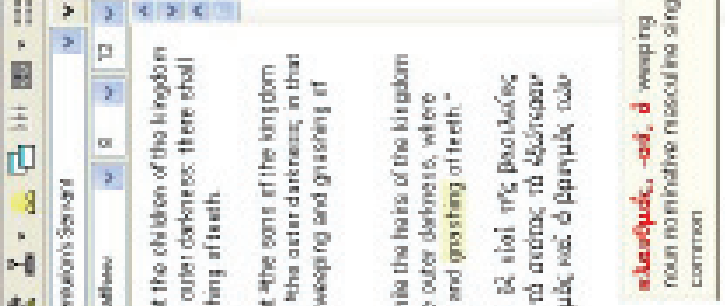

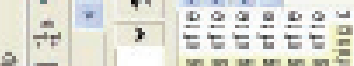
E

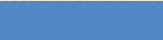

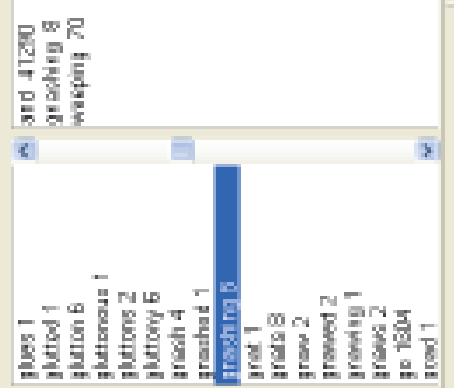




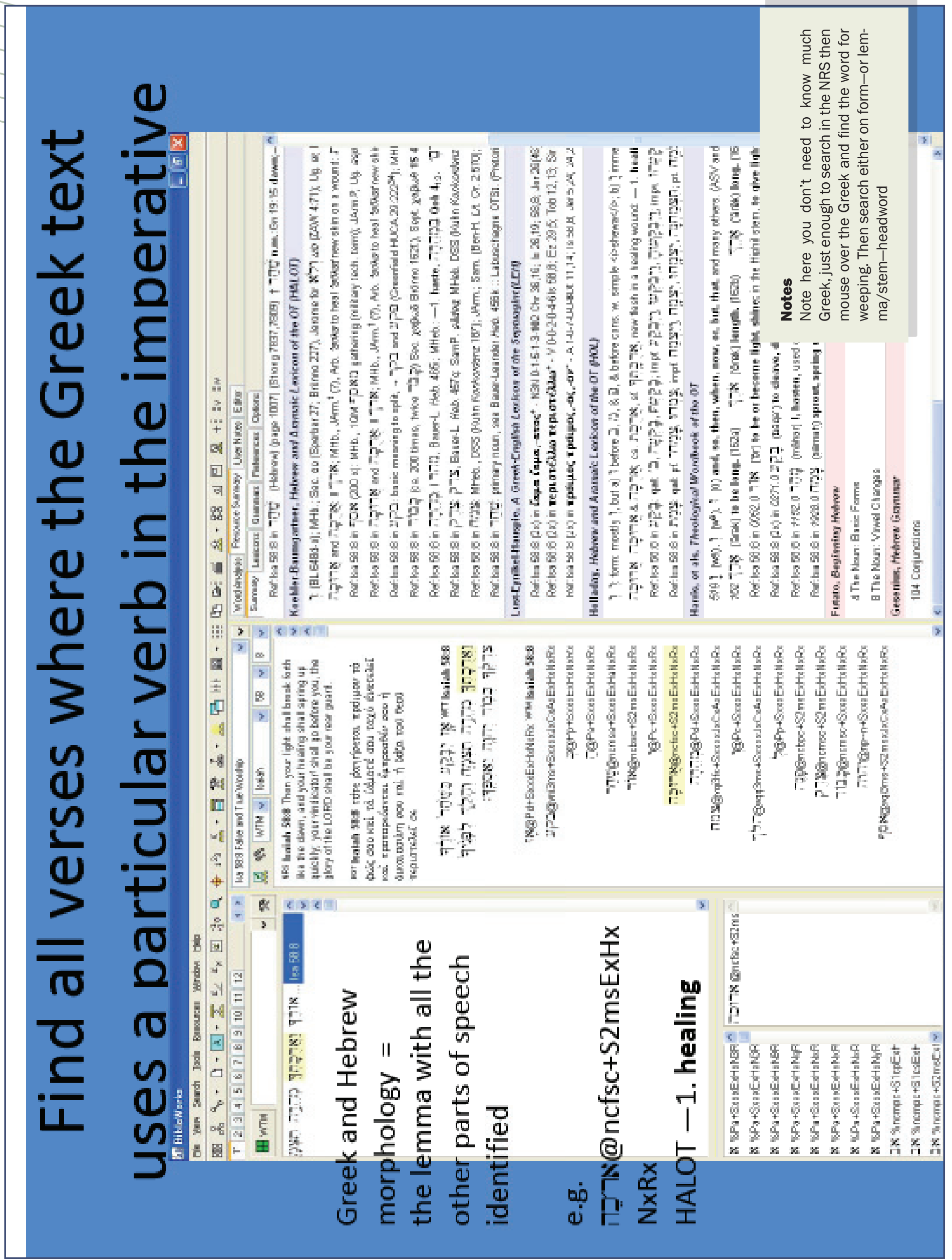




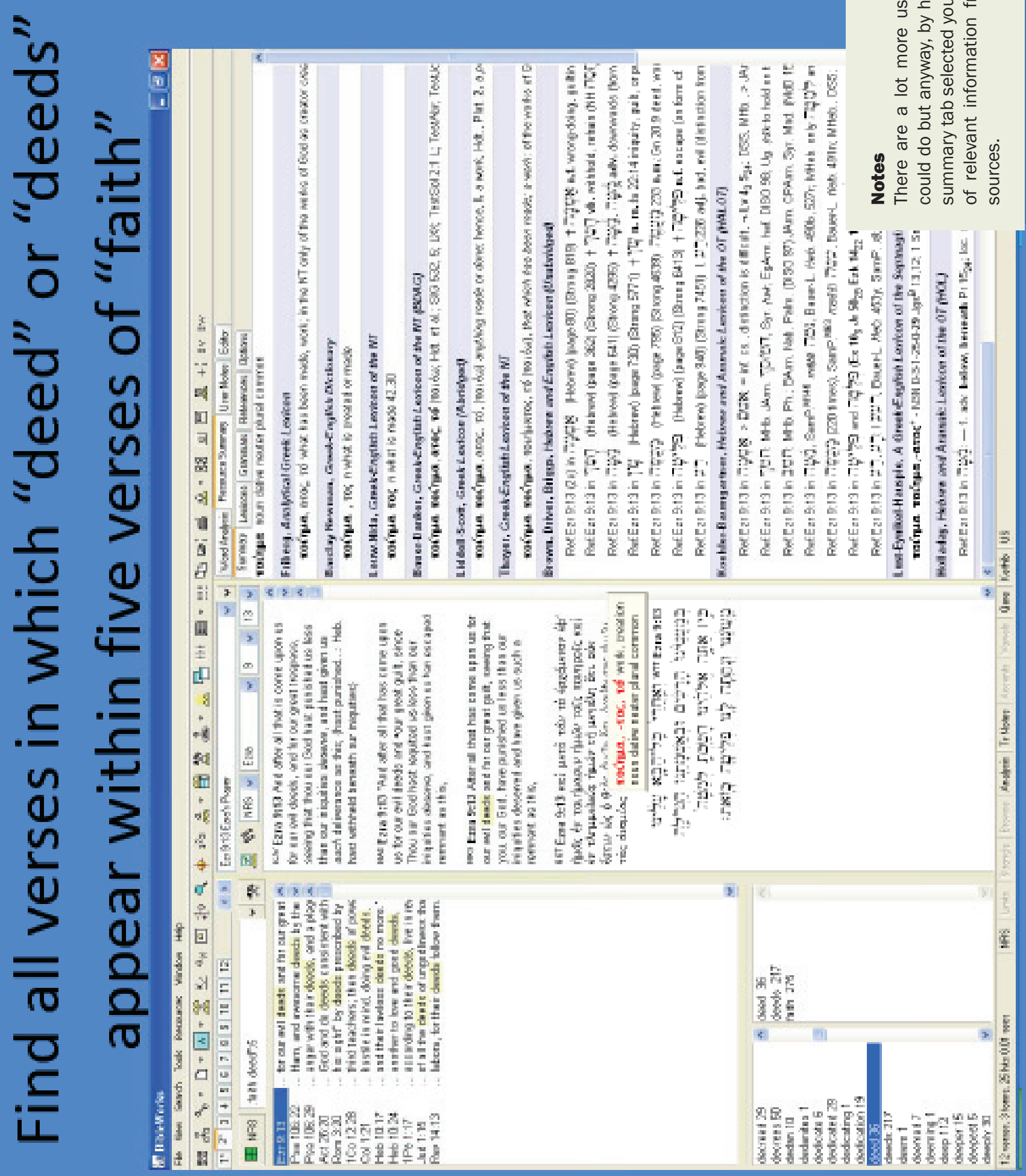




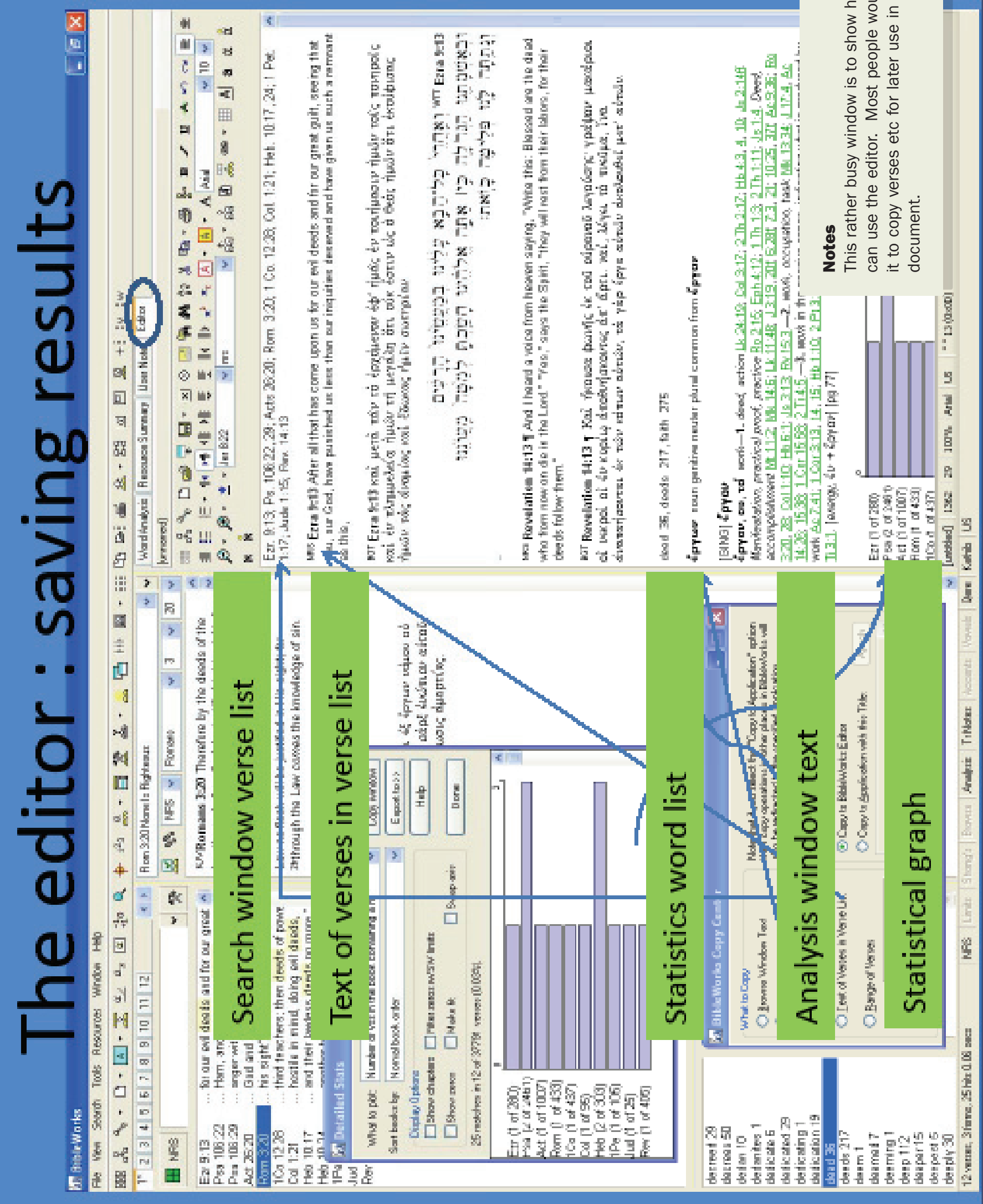




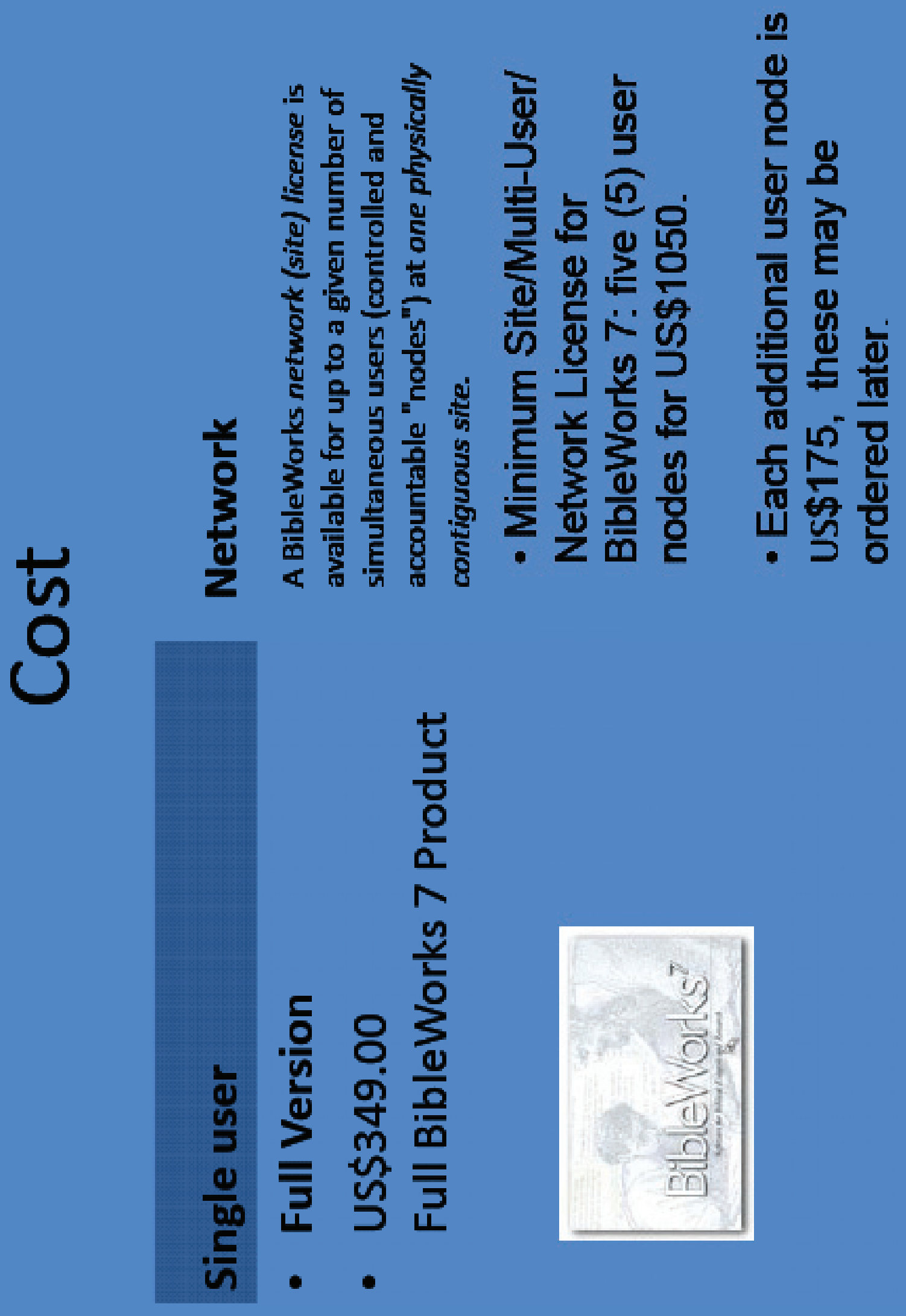




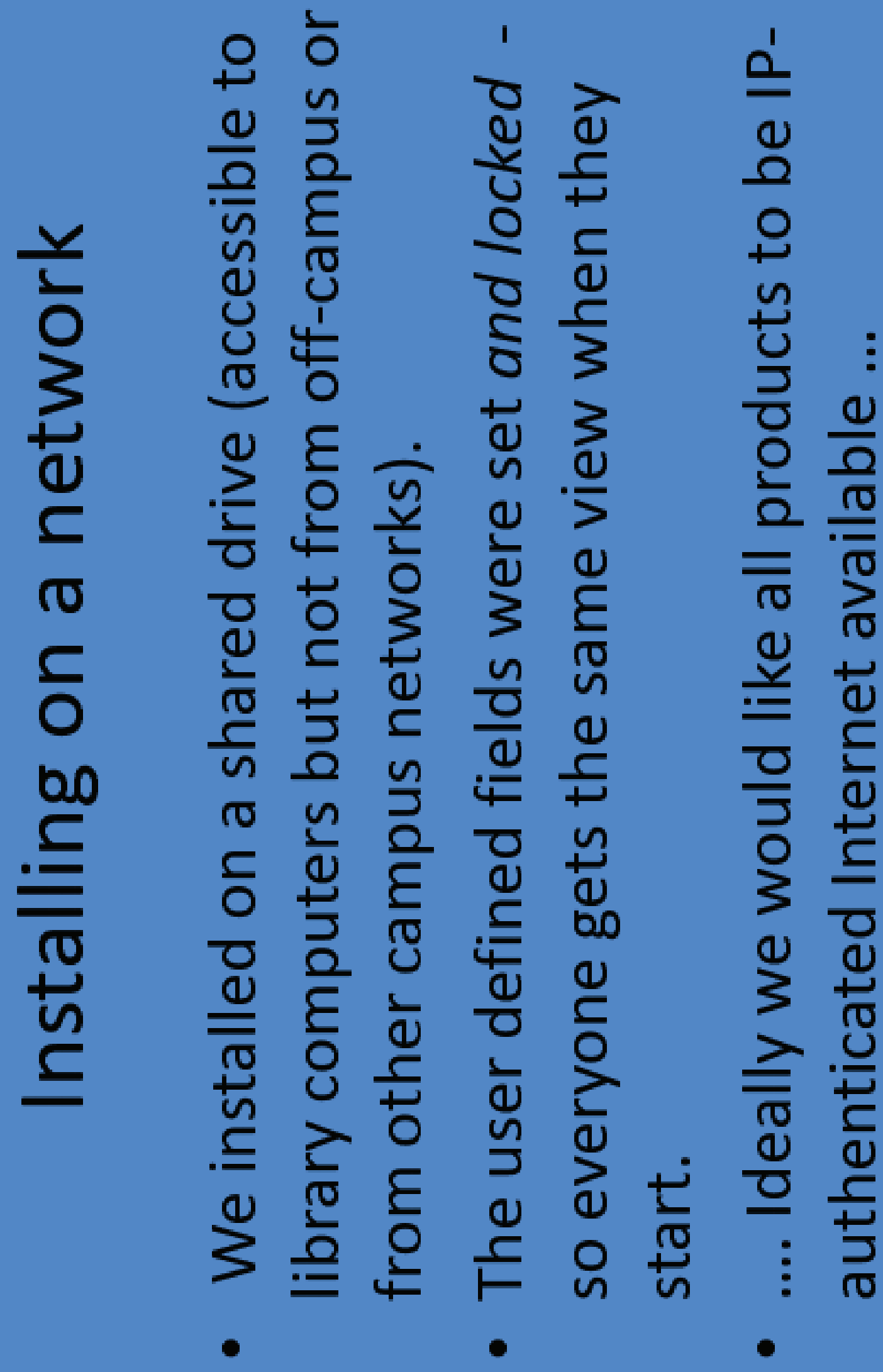




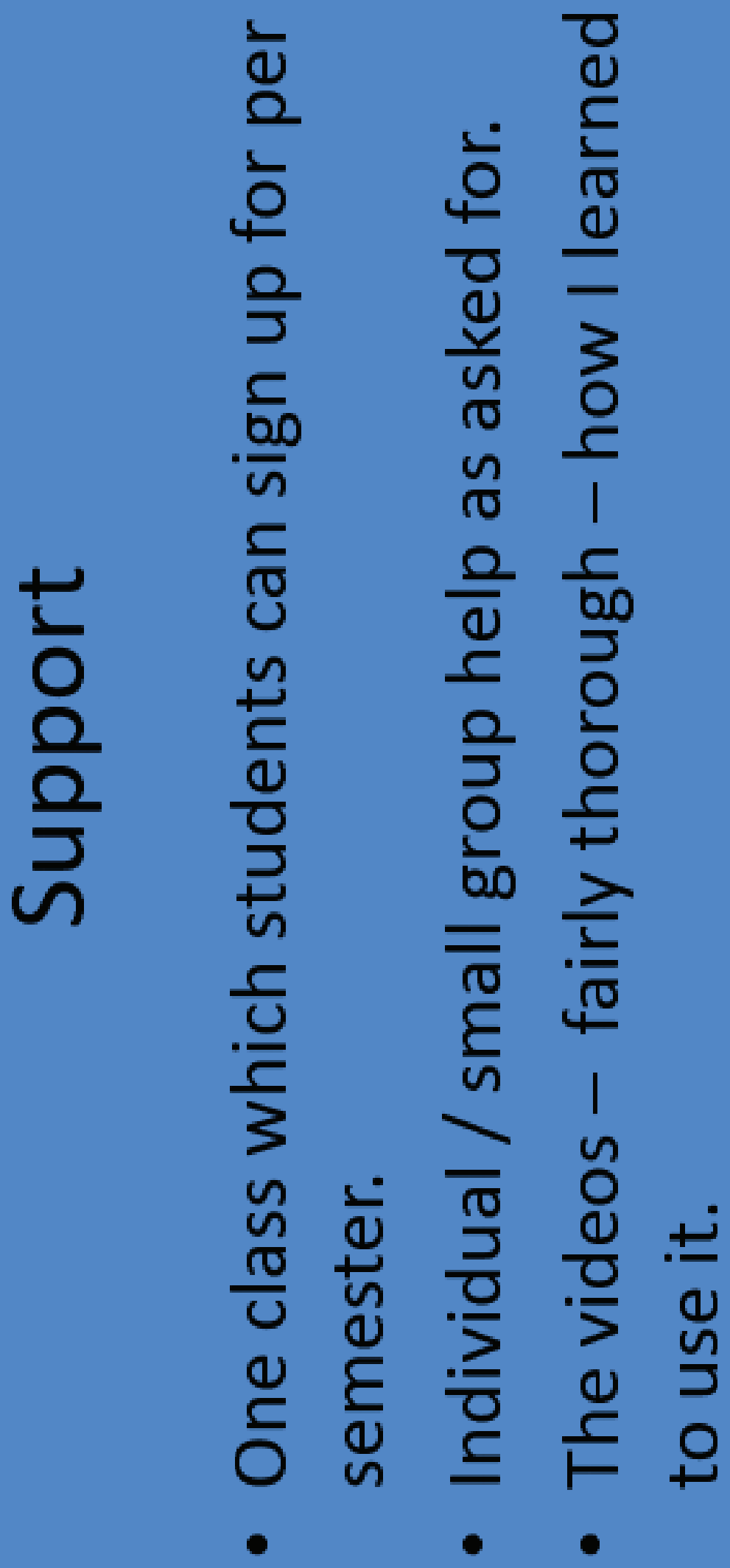

